\title{
Effect of diabetan on blood glucose, glycosylated hemoglobin, lipid profile, liver and kidney function tests of diabetic patients: A clinical, double blind, randomized trial
}

\author{
Behradmanesh Mohammad-Saeed, Ahmadi Mohammad-Ali, Rafieian-kopaei Mahmoud*
}

Medical Plants Research Center, Shahrekord University of Medical Sciences, Shahrekord, Iran,

Accepted 8 November, 2012

\begin{abstract}
Considering the side effects of insulin and oral hypoglycemic agents, this study was performed with the aim of investigating the hypoglycemic effect of Diabetan (glycogol) tablet, which is a blend of Saliva officinalis, Trigonella foenum and ginseng. A double-blind clinical trial was carried out on type-2 diabetic patients who were referred to the Endocrine and Metabolism Clinic of Shahrekord University of Medical Sciences. Eighty type 2 diabetic patients who had not reached the ideal control of the disease were randomly divided into case and control groups. The case group received Diabetan and the control group received placebo tablets three times a day for three months. Glycosylated hemoglobin (HbA1c), lipid profile, liver and kidney function tests were carried out at the beginning and at the end of the trial. The fasting blood sugar (FBS) and $2 \mathrm{~h}$ postprandial (2hpp) glucose were also checked at the beginning and every 2 weeks, for three months and were compared in two mentioned groups. The $2 \mathrm{hpp}$ blood sugar and cholesterol levels decreased significantly in Diabetan treated patients as compared to the control group $(\mathrm{P}<0.05)$. There were no significant changes in glycosylated hemoglobin and FBS between the two groups. Results showed that Diabetan tablets might be beneficial in diabetic patients to reduce $2 \mathrm{hpp}$ and cholesterol. However, higher doses might be needed to decrease fasting blood glucose and glycosylated hemoglobin.
\end{abstract}

Key words: Glycogol tablet, Salvia officinalis, Trigonella foenum, ginseng.

\section{INTRODUCTION}

Diabetes mellitus is considered as the most common endocrine disease; its prevalence which is being increased in human population (American Diabetes Association, 1997). The metabolic aspect of diabetes is characterized by moderate to severe hyperglycemia and impaired metabolism of nutrients, including proteins, carbohydrates and lipids (Yanardag et al., 2002). The side effects of taking insulin and oral hyperglycemic agents have brought about a growing interest among this group of patients for using natural products having antidiabetic activity (Holman and Turner, 1991). Herbs are rich sources of natural antioxidants, and are used in

\footnotetext{
*Corresponding author. E-mail: rafieian@yahoo.com.
}

traditional medicine for the control and treatment of many diseases. The reducing effect of a large number of these plants on blood glucose has been confirmed in animal models and clinical studies (Kazemi et al., 2010; Asgary et al., 2011; Asgari et al., 2012). Studies on animals have shown that more than 400 plant species have hypoglycemic activity and several laboratories are isolating edible herbal hypoglycemic compounds. Among the herbal drugs whose effect on blood sugar reduction has been proved in several human and animal studies are Salvia officinalis, Trigonella foenum and Ginseng (Asgari et al., 2012; Nikravesh and Jalili, 2003; Vuksan et al., 2000). Antioxidant properties of or $S$. officinalis $L$ (Sage) leaves are known (Asgari et al., 2012). Moreover, the hypoglycemic effect of the alcoholic extract of $T$. foenum seeds has been confirmed in laboratory animals 
(Puri et al., 2002; Roghani et al., 2005) and the hypoglycemic effect of its extract has been studied in a limited number of healthy volunteers (Abdel-Barry et al., 2000). In this study, the combination of $S$. officinalis (45 $\mathrm{mg}), T$. foenum seeds $(50 \mathrm{mg})$ and Ginseng $(60 \mathrm{mg})$ was prepared as glycogol tablet and the effect of this compound on blood glucose, glycosylated hemoglobin $(\mathrm{HbA} 1 \mathrm{c})$, lipid profile, liver and kidney function tests were investigated.

\section{METHODOLOGY}

This study was a double-blind randomized clinical trial on type-2 diabetic patients referred to the Endocrine and Metabolism Clinic of Shahrekord University of MEDICAL Sciences. Eighty diabetic type2 patients referred to the clinic who did not have any complications of diabetes (based on description of their medical situation, physical examination, and paraclinical findings) including retinopathy, nephropathy and cardiovascular diseases, and those who had not achieved ideal control of diabetes and were willing to participate in the study, were selected and divided into 2 groups of 40 patients.

Selection of subjects for the medical treatment or placebo control was carried out by convenience random method. The project was done with due consideration to the ethics and obtaining permission from the ethics committee of Shahrekord University of Medical Sciences and obtaining the written consent of participants. Glycogol tablets were given to the first group and the second group took a placebo similar to that of glycogol (3 times a day).

Patients continued receiving their anti-diabetic drugs and other oral medications. First, a questionnaire containing information on age, sex, weight, blood pressure, family history of diabetes and duration of the disease was completed. The treatment period was three months and at the beginning and the end of the study, the $\mathrm{HbA} 1 \mathrm{c}$ and lipid profile as well as liver and kidney function tests were taken. At the beginning of the study and every 2 weeks, fasting blood sugar (FBS) and postprandial sugar were checked. Moreover, indicators relating to medication tolerance and the drugs' side effects were evaluated.

Patients were instructed to follow their type of diet and daily activities during the course of the study. These factors were controlled at the two-week visits as well. Moreover, the symptoms of hypoglycemia and the tasks needed for its treatment were taught. After the end of the 3-month period, patients repeated the tests taken at their arrival into the study and the results were analyzed using statistical tests (paired and independent t-tests and repeated measures test).

\section{RESULTS}

Eighty patients were evaluated in this study and were divided into 2 groups; one received the drug and the other received placebo. Nineteen patients were men and 51 were women. Five patients of each group were excluded due to uncontrolled high blood sugar, need for insulin injection, hospitalization and lack of proper cooperation. On the other hand, two patients in the drug group showed mild gastrointestinal complications without stopping the drug use.

Table 1 illustrates the mean and standard deviation (SD) of variables including age, body mass index (BMI) and duration of the disease in drug and control groups, in
Table 1. Mean and SD of variables age, BMI and duration of the disease in the groups under study.

\begin{tabular}{lcc}
\hline \multirow{2}{*}{ Variable } & \multicolumn{2}{c}{ Group } \\
\cline { 2 - 3 } & Medication & Placebo \\
\hline Age $($ Year $)$ & $53.20 \pm 10.43$ & $51.68 \pm 9.87$ \\
BMI $\left(\mathrm{kg} / \mathrm{m}^{2}\right)$ & $27.77 \pm 4.02$ & $29.53 \pm 4.24$ \\
Duration of the disease & $69.92 \pm 62.33$ & $74.37 \pm 57.74$ \\
\hline
\end{tabular}

None of the above cases were significant $(P>0.05)$.

which none of them has significant difference. $\mathrm{HbA} 1 \mathrm{c}$ value were $7.94 \pm 0.64$ and $7.79 \pm 0$. 60 , respectively in drug and placebo groups at the beginning of the study $(P>0.05)$ and were $7.43 \pm 0.75$ and $7.51 \pm 0.70$ ( $P>0.05)$, respectively, at the end of the study. Table 2 shows the comparison between the mean concentration of FBS and 2-h postprandial blood glucose (2hpp) at the beginning and every two weeks up to three months. The results show a significant decrease in $2 \mathrm{hpp}$ in the medication group as compared to the placebo group. The mean of total cholesterol did not reveal any significant difference at the beginning of the study; however, at the end of study, it was lower in medication group and also lower than its initial value $(\mathrm{P}<0.05)$. Table 3 compares the mean triglyceride, total cholesterol, low density lipoprotein (LDL) and high density lipoprotein (HDL) in the studied groups before and after intervention. Table 4 compares the mean indices of renal function (BUN and creatinine) and liver function (alanine aminotransferase and aspartate aminotransferase) in the medication and placebo groups before and after intervention that showed no significant difference.

\section{DISCUSSION}

This investigation was aimed to study the hypoglycemic effect of glycogol tablet, which is a blend of $S$. officinalis, $T$. foenum and ginseng. The effects of glycogol on lipid profile, liver and kidney function tests were also evaluated in diabetic patients.

In this study, although the fasting blood glucose in drug group was $25 \mathrm{mg} / \mathrm{dl}$ less than in control group; however, the difference was not significant $(P>0.05)$. 2hpp had significant difference in the 12th week of the study $(\mathrm{P}<0.05)$. The lack of significant reduction in fasting blood glucose by medication may be attributed to the drug's ineffectiveness on gluconeogenesis and insulin secretion and significant reduction in $2 \mathrm{hpp}$ by medication in the twelfth week due to lower insulin resistance.

As mentioned, there was no significant change in glycosylated hemoglobin. Since $\mathrm{HbA1c}$ has a considerable correlation with postprandial glucose, the lack of significant result in $\mathrm{HbA} 1 \mathrm{c}$ can be attributed to the mean postprandial blood glucose during the treatment 
Table 2. Comparison between the mean concentration of fasting blood sugar (FBS) and $2 \mathrm{~h}$ postprandial blood glucose (2 hpp) on arrival and every two weeks to three months.

\begin{tabular}{|c|c|c|c|c|c|c|c|c|}
\hline \multirow{2}{*}{\multicolumn{2}{|c|}{ Blood factor }} & \multicolumn{7}{|c|}{ Time (Week) } \\
\hline & & On arrival & $2^{\text {nd }}$ & $4^{r d}$ & $6^{\text {th }}$ & $8^{\text {th }}$ & $10^{\text {th }}$ & $12^{\text {th }}$ \\
\hline \multirow{2}{*}{$\begin{array}{l}\text { FBS } \\
(\mathrm{mg} / \mathrm{dl})\end{array}$} & Medication & $144.25 \pm 43.62$ & $140.71 \pm 30.26$ & $145.34 \pm 32.96$ & $140.45 \pm 28.18$ & $133.34 \pm 38.56$ & $129.25 \pm 35.53$ & $115.00 \pm 45.88$ \\
\hline & Placebo & $142.88 \pm 34.66$ & $138.57 \pm 29.80$ & $137.02 \pm 32.48$ & $133.25 \pm 28.00$ & $140.00 \pm 31.46$ & $141.51 \pm 34.53$ & $143.37 \pm 39.50$ \\
\hline \multirow{2}{*}{$\begin{array}{l}\text { BS2hpp } \\
\text { (mg/dl) }\end{array}$} & Medication & $221.97 \pm 58.43$ & $194.22 \pm 50.96$ & $196.20 \pm 51.44$ & $182.66 \pm 39.55$ & $181.37 \pm 36.97$ & $185.86 \pm 22.04$ & $174.49 \pm 21.01^{*}$ \\
\hline & Placebo & $214.65 \pm 42.83$ & $196.62 \pm 45.27$ & $198.80 \pm 48.13$ & $194.17 \pm 42.74$ & $201.00 \pm 41.35$ & $191.85 \pm 43.44$ & $207.71 \pm 49.25$ \\
\hline
\end{tabular}

Comparison between the mean concentration of FBS and BS2hpp was not significant during different weeks, but ${ }^{*}$ in $12^{\text {th }}$ week BS2hpp in medication group was less than placebo group $(P<0.05)$.

Table 3. The comparison between the mean triglyceride, total cholesterol, low density lipoprotein and high density lipoprotein in the studied groups before and after intervention.

\begin{tabular}{lcccc}
\hline \multirow{2}{*}{ Blood factor } & \multicolumn{3}{c}{ Statistical index } \\
\cline { 2 - 5 } & \multicolumn{2}{c}{ Medication (Mean \pm SD) } & \multicolumn{2}{c}{ Placebo (Mean $\pm S D)$} \\
\cline { 2 - 5 } & Before intervention After intervention & Before intervention After intervention \\
\hline Triglyceride & $175.14 \pm 91.80$ & $180.42 \pm 178.51$ & $168.54 \pm 84.12$ & $149.74 \pm 63.39$ \\
Total cholesterol & $192.68 \pm 35.83$ & $101.57 \pm 39.04^{\star}$ & $190.68 \pm 29.47$ & $181.62 \pm 36.30$ \\
Low density lipoprotein & $110.37 \pm 28.67$ & $101.57 \pm 31.47$ & $105.31 \pm 23.44$ & $102.91 \pm 25.63$ \\
High density lipoprotein & $41.42 \pm 8.35$ & $42.20 \pm 7.63$ & $43.31 \pm 7.98$ & $44.02 \pm 9.16$ \\
\hline
\end{tabular}

${ }^{*} \mathrm{P}<0.05$, in comparison with the initiation of the study and placebo group

Table 4. The comparison between the mean indices of renal function (blood urea nitrogen and creatinine) and liver function (alanine aminotransferase and aspartate aminotransferase) in the medication and placebo groups before and after intervention.

\begin{tabular}{|c|c|c|c|c|}
\hline \multirow{3}{*}{ Blood factor } & \multicolumn{4}{|c|}{ Statistical index } \\
\hline & \multicolumn{2}{|c|}{ Medication (Mean \pm SD) } & \multicolumn{2}{|c|}{ Placebo (Mean \pm SD) } \\
\hline & \multicolumn{2}{|c|}{ Before intervention After intervention } & \multicolumn{2}{|c|}{ Before intervention After intervention } \\
\hline Blood urea nitrogen & $17.91 \pm 6.56$ & $17.28 \pm 5.64$ & $15.74 \pm 6.93$ & $16.20 \pm 5.53$ \\
\hline Creatinine & $0.88 \pm 0.18$ & $0.92 \pm 0.14$ & $0.82 \pm 0.16$ & $0.86 \pm 0.16$ \\
\hline Alanine aminotransferase & $24.17 \pm 9.55$ & $24.85 \pm 7.77$ & $24.14 \pm 6.95$ & $24.37 \pm 6.07$ \\
\hline Aspartate aminotransferase & $22.02 \pm 8.17$ & $21.11 \pm 6.24$ & $19.45 \pm 5.17$ & $20.71 \pm 4.62$ \\
\hline
\end{tabular}

None of the above cases were significant $(P>0.05)$.

which has not been at the desirable level, but the reduction in $2 \mathrm{hpp}$ at the last week may indicate the fact that if the medication continues, there will be probability of reduction in $\mathrm{HbA} 1 \mathrm{c}$ as well.

The results showed that the mean total cholesterol at the end of the study had significant difference in the medication group as compared to the placebo group. Mean triglyceride, LDL and HDL in the studied groups had no significant difference before and after the intervention $(P>0.05)$. The reduction in total cholesterol in the medication group can be an indicator of beneficial effect of this drug on patients who have hyperlipidemia. In addition, glycogol tablets contain $T$. foenum and this herb, in turn contains large amount of tannin and saponin that are able to reduce the intestinal absorption of lipids and maybe part of the effect of glycogol on cholesterol that takes place in this way (Sauvaire et al., 1991). Fortunately, the drug and placebo have had no adverse and unwanted effect on liver and kidneys that shows the drug's safety.

Considering the mentioned issues, it is possible that not achieving a significant result in the reduction of fasting blood glucose and $\mathrm{HbA1c}$ has been due to patients' disloyalty to diets, insufficient and irregular use of the medication and the low level of effective substances in glycogol tablets. However, one should note 
their unwanted side effects, while using high dosages of herbs (Khajehdehi, 2012; Gheissari et al., 2012; Ardalan et al., 2012). It is recommended that further researches should be conducted, regarding the mechanism of glycogol effect on blood glucose reduction in diabetic patients, as a considerable help for patients in order to reduce the use of chemical medications.

\section{ACKNOWLEDGEMENTS}

Goldaru Pharmaceutical Drug Company is appreciated for funding this research and preparing the glycogol as well as its placebo. This paper has been derived from a MD thesis. We also appreciate Mrs. Dehqhanian for her kind cooperation in conducting and implementing the research.

\section{REFERENCES}

Abdel-Barry JA, Abdel-Hassan IA, Jawad AM, Al-Hakiem MH (2000). Hypoglycemic effect of aqueous extract of the leaves of Trigonella foenum-graecum in healthy volunteers. East Mediterr. Health $\mathrm{J}$. 6(1):83-88.

American Diabetes Association (1997). Clinical practice recommendation: screening for diabetes. Diabetes Care 20:2-4.

Ardalan MR, Samadifar Z, Vahedi A (2012). Creatine monohydrate supplement induced interstitial nephritis. J. Nephropathol. 2(1):117120.

Asgari S, Setorki M, Rafieian-kopaei M, Heidarian E, Shahinfard N, Ansari R and Forouzandeh Z (2012). Postprandial hypolipidemic and hypoglycemic effects of Allium hertifolium and Sesamum indicum on hypercholesterolemic rabbits. Afr. J. Pharm. Pharmacol. 6(15):11311135
Asgary S, Moshtaghian J, Setorki M, Kazemi S, Rafieian-kopaei M, Adelnia A, Shamsi F (2011). Hypoglycaemic and hypolipidemic effects of pumpkin (Cucurbita pepo L.) on alloxan-induced diabetic rats. Afr. J. Pharm. Pharmacol. 5(23):2620- 2626.

Gheissari A, Mehrasa P, Merrikhi A, Madihi Y (2012). Acute kidney injury: A pediatric experience over 10 years at a tertiary care center. J. Nephropathol. 2(1):101-108.

Holman RR, Turner RC (1991). Oral agent and insulin in the treatment of NIDDM. In: Pickup J, Williams G, editors. Textbook of diabetes. Oxford: Blackwell Publication pp.467-469.

Kazemi S, Asgary S, Moshtaghian J, Rafieian M, Adelnia A, Shamsi F (2010). Liver protective effects of hydroalcoholic extract of Allium hirtifolium Boiss in rats with alloxan-induced diabetes mellitus. Arya Atheroscler. 6(1):11-15

Khajehdehi $P$ (2012). Turmeric: Reemerging of a neglected Asian traditional remedy. J. Nephropathol. 1(1):17-22.

Nikravesh MR, Jalili M (2003). Anti-diabetic effect of fenugreek seeds extract on lab mice. Birjand Univ. Med. Sci. J. 10(2):5-9.

Puri D, Prabhu KM, Murthy PS (2002). Mechanism of action of a hypoglycemic principle isolated from fenugreek seeds. Indian $\mathrm{J}$. Physiol. Pharmacol. 46(4):456-462.

Roghani M, Baluchnejadmojarad T, Roghani DF (2005). Hypolipidemic effect of aqueous leaf extract of Trigonella foenum-graecum in diabetic rats. Iran J. Endocrinol. Metabol. 7(2):167-171.

Sauvaire Y, Ribes G, Baccou JC, Loubatieeres-Mariani MM (1991). Implication of steroid saponins and sapogenins in the hypocholesterolemic effect of fenugreek. Lipids 26(3):191-197.

Vuksan V, Sievenpiper JL, Koo VY, Francis T, Beljan-Zdravkovic U, Xu Z, Vidgen E (2000). American ginseng (Panax quinquefolius L) reduces postprandial glycemia in non-diabetic subjects and subjects with type 2 diabetes mellitus. Arch. Int. Med. 160(7):1009-1013.

Yanardag R, Bolkent S, Ozsoy-Sacan O, Karabulut BO (2002). Related the effects of chard (Beta vulgaris L. var. Cicla) extract on the kidney tissue, serum urea and creatinine levels of diabetic rats. Phytother. Res. 16(8):758-761. 